


\title{
La resistencia por el derecho a la tierra en Colombia: entre la especificación y el apartheid constitucional*
}

\section{Camilo Ramírez Gutiérrez**}

\section{Resumen}

Este escrito pretende analizar el origen del derecho a la tierra en Colombia desde los movimientos campesinos, es decir, enfatiza en el proceso de creación del conocimiento sobre la compresión, la capacidad y la necesidad de explotar los territorios, no desde el Estado y sus instituciones, sino de los procesos comunitarios, sin perder de vista que la especificación, es entendida como el proceso de positivización en el ordenamiento jurídico colombiano. Para cumplir tal fin, el escrito explora la construcción del derecho a la tierra a finales del siglo XIX y durante el siglo XX y analiza la forma en que la Corte Constitucional ha focalizado sus esfuerzos en garantizar la restitución de tierras de las víctimas del conflicto. Concluye que los esfuerzos normativos por su garantía han sido insuficientes y que persisten los bloqueos que marginan a estos sujetos sociales a un apartheid constitucional.

Palabras claves: despojo de tierras; derecho a la tierra; apartheid constitucional; sujetos campesinos

\section{Resistance for the right of land in colombia: between the specification and the constitutional apartheid}

\begin{abstract}
This article aims to understand the origin of the right of land from the farmers' perspective, which means that it emphasizes the knowledge-building process regarding understanding, capability, and the need to take advantage of territories, not from the State and its institutions, but the community processes; all of the above taking into account how specification is understood as a process of positivization in the Colombian juridic code. Therefore, this article explores the structuring of the right of land by the end of the XIX century and during the XX century. It also analyzes how the Constitution Court has focused its efforts to guarantee land restitution to the conflict victims. It concludes that the normative efforts to ensure land restitution have been insufficient and that there are still obstacles marginalizing these social subjects to constitutional apartheid.
\end{abstract}

Key words: Looting of land; right of land; constitutional apartheid; subjects; farmers.

\section{A resistência pelo direito à terra na colômbia: entre a especificação e 0 apartheid constitucional}

\section{Resumo}

Este artigo pretende analisar a origem do direito à terra na Colômbia desde os movimentos agrícolas, ou seja, enfatiza no processo de criação do conhecimento sobre a compreensão, a capacidade e a necessidade de explorar os territórios, sem partir do Estado e suas instituições, mas sim desde os processos comunitários, sem perder de vista a forma na qual a especificação, entendida como o processo de positivação no ordenamento jurídico colombiano. Para alcançar tal objetivo, o texto explora a construção do direito à terra no final do século XIX e durante o século $\mathrm{XX}$ e analisa a forma na qual o Supremo Tribunal Federal enfocou seus esforços para garantir a restituição de terras das vítimas do conflito. Conclui que os esforços normativos por sua garantia têm sido insuficientes e que persistem os bloqueios que marginalizam a estes sujeitos sociais a um "apartheid constitucional".

Palavras-chave: Expropriação de terras; Direito à terra; Apartheid constitucional; Sujeitos; Agricultores.

* $\quad$ Artículo de reflexión.

** Profesor de la profesor de la Universidad del Bosque, Colombia. Miembro fundador del Instituto de Derechos Humanos Capítulo Colombia. Actualmente, trabaja en la Sección de Revisión del Tribunal para la Paz, de la Jurisdicción Especial para la Paz (Colombia). Abogado de la Universidad de Bogotá Jorge Tadeo Lozano, especialista en DDHH y DIH y magíster en derecho de la Universidad Nacional de Colombia. correo electrónico: ancramirezgu@unal.edu.co. ORCID: https://orcid.org/0000-0002-0410-6174. Academia: https://unal.academia.edu/CamiloRamirezGutierrez

Cómo citar este artículo: Ramírez Gutiérrez, C. (2021). La resistencia por el derecho a la tierra en Colombia: entre la especificación y el apartheid constitucional. Estudios de Derecho, 78 (172), 121-147

Doi:10.17533/udea.esde.v78n172a05

Fecha de recepción: 29/01/2021 Fecha de aceptación: 27/04/2021 


\section{La resistencia por el derecho a la tierra en Colombia: entre la especificación y el apartheid constitucional}

\section{Introducción}

La lucha por los derechos sociales en Latinoamérica tiene su origen en la política popular, es decir, en los movimientos de base conformados por campesinos sin tierra, trabajadores y artesanos a inicios del siglo XX, quienes desde la organización social, sindical y política presionaron a las elites criollas para crear o reformar los sistemas de salubridad pública, los derechos laborales y la repartición y adjudicación de la propiedad rural para quien la trabaja (Gaviria, 2002). Existen varios referentes de este constitucionalismo social, y de su especial énfasis en la distribución y acceso a la tierra. Por ejemplo, la Constitución de Querétaro en México apareció como una pretensión indígena-campesina, en torno a los movimientos revolucionarios que la gestaron pues, a diferencia de los movimientos burgueses entre los siglos XVII y XIX, estos no estaban influidos por la cultura francesa o norteamericana, sino por las contradicciones sociales existentes en las relaciones de trabajo y en la distribución de la propiedad ${ }^{1}$.

Sin embargo, el concepto emergente de derechos sociales llegaría de la mano de la ideología socialista campesina y de todas sus ramificaciones en el continente, luego de la Constitución mexicana de 1917 (Guilli, 2007). Por su parte, el siglo XX desarrolló el concepto en Europa a través de dos acontecimientos sincrónicos, como fueron la revolución leninista en Rusia de 1917 y la Constitución de Weimar de 1919. Dicho contexto histórico marcó una tendencia contrahegemónica en el desarrollo de los derechos considerados individuales, pues, en la práctica, la oposición del sistema capitalista a los regímenes considerados como socialistas/ comunistas, llevó a la desestructuración de la categoría de derechos sociales.

Durante la Guerra Fría estos enfoques sobre los derechos estuvieron atados a factores políticos, bélicos e ideológicos hasta la caída de la URSS (Kissinger, 2016). En términos generales, los modelos liberal democrático y socialista fue-

1 Al respecto véase el libro: Querétaro. Historia de las instituciones jurídicas. Recuperado de: https://archivos.juridicas. unam.mx/www/bjv/libros/7/3135/7.pdf 
ron asimilados por el capitalismo, tanto el régimen republicano de libertades, como el socialista de prestaciones sociales, en una mixtura que dio origen al denominado constitucionalismo moderno.

Estos hechos incidieron en la Constitución Política de 1991, en especial, en el tardío acogimiento de una teoría de derechos sociales fundamentales, tras una larga influencia de los Estados Unidos en la política de seguridad interna durante la Guerra Fría (Estrada, 2015; Uribe, 2007). Solo hasta 1991, con la caída del régimen soviético y el boom del reformismo constitucional bajo las directrices del Consenso de Washington, se promulgó en Colombia un nuevo texto político con un catálogo de derechos sociales, cuya aplicación puede ser exigida por los ciudadanos a las autoridades públicas (Cruz, 2010; Estrada, 2015).

A pesar de la introducción tardía de esos derechos al régimen jurídico colombiano, es fundamental reconocer que durante toda la historia republicana $y$, sobre todo, luego de los años cuarenta, se iniciaron varios movimientos de masas que exigieron el derecho a la tierra y otros derechos sociales, como las garantías laborales, la soberanía alimentaria y el derecho a una vivienda familiar, en un país que, para la época, era mayoritariamente rural (Uribe, 2017). En este contexto, entre la creciente población campesina, se gestó la promoción del concepto "la tierra pa el que la trabaja", el cual fue desarrollado inicialmente por los campesinos mexicanos que impulsaron la Constitución de Querétaro ${ }^{2}$ y, posteriormente, extendido a todos los movimientos campesinos latinoamericanos.

En Colombia, tras el accionar de los movimientos agrarios de toma de tierras, las elites oligarcas criollas se opusieron a la materialización efectiva de los derechos para estas comunidades campesinas, pues eran ellas las poseedoras o propietarias de grandes extensiones de latifundios en el país y, en algunas ocasiones, instrumentalizaron a estos movimientos para colonizar lugares agrestes y selváticos del territorio nacional ${ }^{3}$ (Centro Nacional de Memoria Histórica [CNMH], 2010).

En efecto, los procesos de violencia organizada son una referencia obligada al escribir sobre el derecho a la tierra, no solo en Colombia sino en el mundo. En el caso colombiano, la violencia no ocupa una fracción temporal, sino que es una constante, pues la confrontación constituye la piedra angular para la negación de derechos sociales de las comunidades rurales, al ser uno de los motivos y, a la vez, una de las excusas para que el Estado no garantice estos derechos en las periferias.

2 Uno de ellos fue Emiliano Zapata, quien al frente del Ejército Libertador del Sur, reclamaba a Madero haber incumplido lo ofrecido en cuanto a la devolución de tierras a las comunidades indígenas y agrarias del Estado de Morelos; en tanto en Chihuahua, al norte, Pascual Orozco acusaba al presidente de corrupción y traición al país.

3 Entre ellos, revisar: (CNMH) Una nación desterrada. Informe sobre desplazamiento forzado en Colombia (2015); (CNMH) Con licencia para desplazar. Masacres y reconfiguración territorial en Tibú, Catatumbo (2015 a); Tierras y conflictos rurales. Historias políticas agrarias y protagonistas (2016). 
La consagración normativa del derecho de propiedad y del derecho al acceso progresivo a la propiedad rural ha estado relacionada con la confrontación bélica que ha mantenido el país entre actores estatales, civiles e ilegales, a lo que se suma la carencia de sistemas sociales de atención en salud, educación, vivienda y trabajo en las zonas rurales del país.

En ese contexto, este escrito pretende analizar el origen del derecho a la tierra en Colombia desde los movimientos campesinos, es decir, enfatiza en el proceso de creación del conocimiento sobre la compresión, la capacidad y la necesidad de explotar los territorios, no desde el Estado y sus instituciones, sino desde los procesos comunitarios (De Sousa, 2009). Este método no pugna con la categoría "derecho", propia de la visión liberal del Estado, pues se parte de su reconocimiento, por lo cual, analiza la escisión entre lo que refiere la normativa legal y lo que se entiende desde la visión del campesinado.

Para cumplir tal propósito, se acude a fuentes secundarias con el fin de explorar los relatos campesinos a partir de la organización social desde mitad del siglo XX, consignados por varios investigadores nacionales, así como su interacción con la situación sociopolítica del país, principalmente con la guerra. Además, se analizan algunas providencias proferidas por la Corte Constitucional en el seguimiento a la Sentencia T-025 de 2004, que declaró el estado de cosas inconstitucional, producto del despojo masivo de territorios por parte de grupos armados ilegales.

Ante el panorama jurídico potencialmente alentador que sugieren los recientes cambios institucionales en el país, el escrito sostiene que, en materia de garantía del derecho a la tierra, Colombia ha vivido un verdadero apartheid constitucional.

\section{La tierra y la propiedad, temas en controversia. Herencias del siglo XIX y XX}

Para Hobsbawn (1968), el sujeto campesino aparece como producto del feudalismo y el latifundismo, es decir, como una manifestación de la organización de la sociedad sujeto a las formas de producción. Es así como su forma organizativa depende de la fuerte ligazón de los núcleos familiares con la naturaleza y la fuerza de trabajo que estos puedan proporcionar. ${ }^{4}$. De igual manera, desde la Edad Media estas interrelaciones sociales habían producido dinámicas asociativas de las comunidades campesinas, las cuales surgieron con el fin de dar paso a formas de subsistencia, en términos de soberanía alimentaria, de comercio e intercambio básicos de técnicas y tecnologías de producción, hasta formas autóctonas de distribución de la tierra. Lo anterior dio como resultado la categoría de análisis

4 Para un estudio de caso sobre tal relación a propósito de las víctimas del despojo en los Montes de María, véase: Ramírez, G. C. (2015). Víctimas de despojo de tierras en el marco de los procesos de restitución de tierras llevados por la Comisión Colombiana de Juristas [Entrevista]. 
del pequeño propietario agrario, el cual está subordinado al gran latifundista (Marx, 2014; Camaroff, 2009).

En Colombia la relación entre la tierra y el sujeto social campesino tiene como génesis la colonización, y como base las mezclas de mestizos, indígenas, criollos, entre otros, que dieron lugar a esta nueva categoría social que desarrollaba actividades relacionadas con la producción, manejo y transformación de la tierra en el territorio nacional. En este relacionamiento aparecieron, a finales del siglo XIX, los conflictos sociales y políticos, además de la estructuración de clases relacionadas con el latifundio, como los terratenientes, productores y campesinos.

Como lo relata la antropóloga María Victoria Uribe (2017) la conformación, tanto de las clases políticas, como de las sociales, estuvo fuertemente marcada por el establecimiento de dos mundos: el rural y el urbano. Siguiendo esta apreciación, es común escuchar entre los sociólogos y politólogos colombianos que la historia de la violencia política ha estado mediada por la disputa por la tierra. Gutiérrez (2014), sostiene que a finales del siglo XIX los campesinos estaban en mejor posición social que otras clases, por lo que se encontraban en un estado favorable respecto de la legislación vigente gracias a la república liberal que regía y que le daba un gran valor a la propiedad, en contraste con otros países latinoamericanos (Palacios, 2014).

En el siglo XVIII, a inicios de la época republicana, varias ideas socialistas permearon a algunos miembros de las instituciones del Estado, quienes pusieron en entredicho las consideraciones sobre la tierra ${ }^{5}$. El senador liberal Gerardo Molina (1984) señaló que:

(...) en época posterior, la de la República, el elemento socialista volvió a aparecer, bien como manera de vida y de trabajo de los indígenas, bien como ideología. En este último aspecto aquel elemento fue manifiesto, y así los jóvenes que surgieron al definirse la revolución de 1849, profundamente anticolonial, y al entrar en contacto en las Sociedades Democráticas con la clase trabajadora de la época, los artesanos, difundieron las ideas socialistas, esta vez procedentes de Europa. Uno de esos jóvenes, Murillo Toro, (...) una muestra de la sensibilidad socialista (...) antes de que virara hacia el individualismo, lo da el hecho de que, al presentar al Congreso en su proyecto sobre la Reforma Agraria, sostuvo que el cultivo es el verdadero fundamento de la propiedad y que nadie debe poseer más tierras que la necesaria para subsistir. (p. 138)

5 "Lo que sucediera con la tierra determinaba la vida y la muerte de la mayoría de los seres humanos entre los años 1789 y 1848. Como consecuencia, el impacto de la doble revolución sobre la propiedad, la posesión y el cultivo de la tierra, fue el fenómeno más catastrófico de nuestro período. Ni la revolución política ni la económica pudieron menospreciar la tierra, a la que la primera escuela de economistas -la de los fisiócratas- consideraban como única fuente de riqueza, y cuya transformación revolucionaria todos juzgaban de necesaria precondición y consecuencia de la sociedad burguesa, sino de todo el rápido desarrollo económico" (Hobsbawn, 2018, pp. 53-54) 
Sin embargo, la avanzada de los derechos por la propiedad de los campesinos se encontraba con el establecimiento y fortalecimiento de una clase política conservadora y latifundista, fruto de aquella lucha entre, por un lado, los sectores políticos radicales, propios del liberalismo federalista y, por otro lado, los centralistas, herederos de las prácticas realistas de la corona española ${ }^{6}$. La superación de esta etapa, como lo describe María Victoria Uribe (2017), se dio en medio del tránsito al siglo XIX, cuando los dos partidos colombianos concentraron el poder político alrededor de las elites urbanas y rurales, lo que inició la disputa por la posesión del territorio, y con ello la concentración de la tierra, en una violencia que no se fundamentó en guerras civiles revolucionarias, sino en la lucha por la repartición de la burocracia y la incorporación de cada sector al aparato institucional. En dicho contexto, en Colombia el derecho a la tierra se ha definido a través de dos elementos que han tenido protagonismo; por un lado, la coerción y por el otro, la regulación (Gutiérrez, 2014), por lo cual en el siglo XX se puede hablar de la apropiación de la tierra y de la violencia como hechos sincrónicos.

La competencia por el poder entre los partidos tradicionales, liberales $v s$. conservadores, tuvo dos grandes momentos; el primero, en la presidencia del liberal Olaya Herrera entre 1930 y 1934, periodo en el cual varios de los campesinos de la región andina fueron sus adeptos. El segundo, tuvo lugar en el período denominado La Violencia, luego de la muerte del caudillo liberal Jorge Eliecer Gaitán (Uribe, 2007). Durante la primera contienda se produjo en la región andina, especialmente en el Sumapaz y Tequendama, departamento de Cundinamarca, un movimiento de resistencia campesina que, con una tutela clara de los liberales, defendió los derechos a la propiedad de la tierra pa quien la trabaja (Marulanda, 1991).

Bajo esta lógica, entre los campesinos apareció una nueva clase de sujetos sociales denominados "colonos", personas trabajadoras del campo, pero que no tenían propiedad. Estos sujetos fueron utilizados por varios terratenientes para ganar espacio en los territorios agrestes de la geografía nacional. Gutiérrez (2014), trae a colación la investigación realizada por Catherine Legrand (2017) sobre el problema de la tierra en Colombia y la relaciona con la influencia de la legislación que configuró los baldíos en cabeza del Estado, hecho que permitió que los terratenientes despojaran a los campesinos colonos sus tierras impunemente.

En distintas regiones del país, con la aquiescencia, tolerancia y omisión del Estado, se realizaron despojos de tierras a través del sistema de apropiación y recuperación de baldíos, lo que forjó una disputa histórica por el derecho a la propiedad de la tierra que se ha mantenido hasta la actualidad.

La existencia de movimientos campesinos en medio de la agitación política imprimió en estos sujetos sociales dos tipos de ideologías respecto a la posesión

6 Cfr. Entre otros autores se encuentran: Gutiérrez, F. (2014). El orangután con sacoleva. Cien años de democracia y represión en Colombia (1910 y 2010). Bogotá: Debate. Legrand, C. (2017). Colonización y protesta en Colombia (1850-1950). Bogotá: Universidad de los Andes. Uribe, M. (2007). Salvo el poder todo es una ilusión. Bogotá: Instituto Pensar. 
de la tierra. La primera, de raigambre liberal, derivada de lo que Spivak (1998), señaló como una conciencia subalterna historiada, pues como se indicó, de la primera ola de movimientos de resistencia campesina y de la misma concreción del sujeto social, la tierra como propiedad es un elemento sine qua non de la cultura campesina. La segunda, se remonta al periodo de La Violencia (1948-1958) (Sánchez, 1984) y periodos posteriores del conflicto de guerrillas, época en la cual la influencia del partido comunista sobre los movimientos, en especial en Chaparral, Tolima, llevó a una conciencia colectiva emergente, que les permitió desprenderse de su condición de subalternidad (Uribe, 2007) y, sobre todo, del interés liberal individualista (Cano, 2015).

Esta deconstrucción del sujeto campesino y su dependencia propiedad-tierra, como conciencia liberal, propia de un sujeto europeo feudal preilustración, se trastornó con la imbricación de la conciencia colectiva sobre las formaciones sociales, lo que afectó la interrelación del campesinado con la naturaleza y las formas de producción. Así, se constituyó una nueva correspondencia marginal para la legislación y el Estado, pero real para las comunidades, como es la visión comunal sobre la tierra, y su concepto territorio-comunidad.

Ante este modus social Alfredo Molano (2013), resalta la colisión de este sujeto social en un mundo liberal, pues: "[h] ay dos horizontes contrapuestos: el campesino, modesto en la escala, limitado en la acumulación de capital, pero estable desde el punto de vista social, y el minero empresarial, ambicioso, devastador y respaldado incondicionalmente por el gobierno" (p. 20). Pues si bien, como se indicó, el campesinado como sujeto social nace como pequeño propietario, y bajo esa consigna se establece su relación de explotación con la tierra, los estudios sociales han demostrado ${ }^{7}$ que esta interacción con el tiempo fue transformada, de tal forma que hizo que la tierra fuera más allá del derecho de propiedad, y que se diera paso en el lenguaje a categorías como territorio, comunidad, mercados campesinos y, sobre todo, cultural campesina.

Así las cosas, la visión de la tierra como elemento de la cultura campesina y trascendente del concepto de propiedad se desarrolló en los territorios. Entonces, aun cuando las luchas se gestaban alrededor del derecho de propiedad, las vivencias se construían en torno a ese recurso sobre el cual las comunidades campesinas se alimentaban, se abastecían y sobre el que se desarrollaban como colectivo humano: el territorio (Ninet, 2017) ${ }^{8}$.

7 (Báez, 2015; Holdcroft, 1991; Molano, 2013, entre otros).

8 En el caso mexicano, la Constitución revolucionaria de Querétaro dio lugar a la nacionalización y un nuevo concepto de propiedad privada revolucionario, presentada en el primer párrafo del artículo 27, que afirma: la propiedad de las tierras y aguas comprendidas dentro de los límites del territorio nacional corresponde originariamente a la nación, la cual ha tenido y tiene el derecho de transmitir el dominio de ellas a los particulares, constituyendo la propiedad privada" (Constitución Política del Estado Libre y Soberano De Querétaro Arteaga, 1917). Véase también: Ninet (2017). 
En ese marco, la disputa por la tierra se ha dado desde la proposición de intervenciones a la propiedad rural hasta los márgenes del derecho y de la violencia, pues esta discusión ha tenido lugar en escenarios contrarios e inconsecuentes. Desde la época de La Violencia hasta los tiempos del conflicto armado, se ha exigido un cambio del derecho a la propiedad, el cual tiene por característica la movilización de sectores con oponibilidad política. En la primera, con la extensión de la frontera agrícola por medio del latifundismo de los grandes señores, en su mayoría conservadores y, en la segunda, más recientemente, con la entrada de las guerrillas marxistas que exigían la reforma rural integral y las contrarreformas rurales paramilitares (Zelik, 2015).

Es así como, en el año de 1936, dentro del Congreso de la República, el senador liberal Gerardo Molina abogó por la reforma constitucional del derecho a la propiedad, bajo el precepto denominado la función social (Barreto, 2011). Dicha modificación tenía como objetivo regular la propiedad de aquellos latifundios improductivos, a través de la expropiación para luego adjudicarlos a los campesinos sin tierra, pero mantuvo el significado liberal de pertenencia. Por su parte, las comunidades campesinas crearon formas organizativas de colonización y resistencia colectiva que buscaban la objetivación de los territorios, el equilibrio entre medio ambiente y explotación, y la no intervención de proyectos minero-energéticos que afecten la biodiversidad y las fuentes hídricas (Molano, 2013).

Por la falta de respuesta de la institucionalidad a dichas manifestaciones, varias comunidades prefirieron el aislamiento y la autosostenibilidad, por lo que fueron denominadas por varios de los sectores políticos como "repúblicas independientes" (Molano, 2016). Legrand (2017), señala que este periodo de disputas por la tierra tuvo una ruptura con la expedición de la Ley 200 de 1936, o Ley de Tierras, pues fue un periodo de alta mercantilización de los productos agrícolas, a través de la exportación de café, la expansión ganadera y la construcción de ferrocarriles. Además, llevó a un programa de parcelación que influyó en la "evolución" de las relaciones laborales en el campo. Adicionalmente, esta ley tuvo un efecto sobre la propiedad agraria, pues consagró la posibilidad de adquirir por prescripción tierras ocupadas.

En conclusión, no hubo relación alguna entre las leyes de propiedad rural y las formas de producción, desde la Colonia hasta mediados del siglo XIX, lo que privilegió, en esa etapa de la historia agrícola, la visión jurídica de la tierra de parte del Estado y de las elites, respecto a la construcción del territorio desde los campesinos. Así mismo, la creación del latifundio o de la gran hacienda determinó el corazón de la organización económica, social y política del país durante el siglo XIX y las primeras décadas del siglo XX, con lo cual fundamentó las luchas tanto del centro, como de la periferia interpartidistas (Reyes, 2016). Por tanto, si bien la relación tierra-sujeto se expresó a través del derecho a la propiedad, la construcción campesina del territorio se mantuvo en la práctica. 


\section{Conflicto, tierra y derechos en Colombia a finales del siglo XX e inicios siglo XXI}

Colombia atraviesa un momento histórico debido a la firma del Acuerdo de Paz con la guerrilla de las Fuerzas Armadas Revolucionarias de Colombia - Ejército del Pueblo (FARC-EP), en el año 2016, acto que puso fin a un conflicto sociopolítico reconocido por ser una de las confrontaciones armadas más antiguas del mundo, solo tres conflictos le disputan a Colombia el triste récord de la longevidad: la confrontación por el Cachemira entre la India y Pakistán que inició en 1947, la guerra entre Israel y Palestina de 1948 y la guerra de secesión en Birmania de 1960 (Pizarro, 2004).

Sin embargo, no se pueden desconocer los efectos de la guerra librada entre el Estado, las guerrillas y los grupos paramilitares, así como las repercusiones que esta ha tenido respecto de las comunidades campesinas, el campo y sus territorios.

En este apartado se revisan los rezagos que esta confrontación social, económica y política dejó en las organizaciones campesinas y en las instituciones jurídicas que rodean la concepción del derecho a la tierra o al territorio, en contraposición al concepto de propiedad rural y al acceso progresivo a este, desarrollado a partir de la Constitución Política de 1991.

Desde inicios del siglo XXI la categoría jurídica de víctima adquiere relevancia para concretar los derechos sobre la tierra o la propiedad rural. Lo anterior, debido a que una de las afectaciones más grandes del conflicto ha sido el desplazamiento forzado de personas y, con ello, el despojo de tierras. Según datos de la Unidad para la Atención y Reparación Integral a las Víctimas para el año 2019 más de siete millones de personas habían sido víctimas de desplazamiento.

En cuestión de tierras, según estableció la Comisión de Seguimiento a la Sentencia T-025 del 2004, en el período comprendido entre 1998 y 2008 se abandonaron o despojaron 5,3 millones de hectáreas. Además, los expertos de la Comisión Histórica del Conflicto y sus Víctimas $(2015)^{9}$, indicaron que, el desplazamiento forzado no es un fenómeno nuevo en el contexto de violencia del país, pues en el periodo entre 1948 y 1953, época denominada La Violencia, casi dos millones de personas fueron desplazadas forzadamente y nunca retornaron. No obstante, el mayor momento de impacto de la trasgresión del derecho internacional humanitario y del derecho internacional de los derechos humanos fue en los años noventa, cuando los distintos grupos armados hicieron del desplazamiento forzado un instrumento común de guerra que escaló la intensidad de la violencia y, con ello, el número de víctimas del conflicto (Rodríguez, 2008). En efecto, a finales de 1996, comenzó un éxodo masivo en varias partes del país,

9 Estrada, J. (2015). 
en especial en los departamentos septentrionales y occidentales de Antioquia, Cesar y Chocó, mientras que "en el caso de los desplazamientos individuales, el momento de mayor gravedad ocurrió entre 2000 y 2002" (Rodríguez Franco y Rodríguez Garavito, 2015, p. 57).

En este contexto también se mantuvo una comprensión liberal de la tenencia de la tierra. Como lo manifiesta Buis (2020):

En términos jurídicos, el concepto de propiedad pone en juego una relación particular directa e inmediata entre las personas y las cosas. En efecto, desde el derecho romano parece claro que la noción de dominium implicaba un vínculo que suponía el señorío jurídico que un individuo posee respecto de aquellos bienes inmuebles o muebles que, como consecuencia de esas potestades, caen bajo su ámbito de control, uso, goce y disposición. (p. 45)

La estabilidad que brinda esta concepción es clave para entender los encuentros y desencuentros del sujeto campesino y la tierra, como elemento relacional, y como ficción jurídica en medio de las confrontaciones del conflicto armado.

\section{La tierra pa el que la trabaja}

A finales de los años sesenta en Colombia se reactivaron las luchas campesinas por la tierra alrededor de la denominada toma de tierras y la consolidación de las organizaciones de sujetos agrarios. El líder de la ANUC Jesús María Pérez (2010) indica que la principal reunión de campesinos en pro de sus intereses fue la Asociación Nacional de Usuarios Campesinos (ANUC), que incidió en la creación del programa de Desarrollo Rural Integrado (DRI) a finales de la década del 70 y en el Plan Nacional de Rehabilitación (PNR) en la década del 80, como estrategia contra la violencia, espacios que "sirvieron de pretexto para que la organización campesina planteara sus objeciones a los proyectos gubernamentales y formulara sus propias propuestas" (Reyes, 2016, p. 53).

Dichos planteamientos se alinearon con las formas de concepción del derecho social sobre la tierra, no como territorio, o como concepto amplio de la noción de comunidad campesina, sino desde la estructuración de la propiedad privada, la parcelación y la producción con fines económicos. Esta cuestión fue valorada por los gobiernos de la época y motivó la producción de políticas de adjudicación de baldíos bajo la condición de que estos, como futura propiedad agraria, deberían ser explotados y puestos en producción.

La situación trajo como consecuencia que en el espectro sociojurídico se empezaran a definir ciertas categoría sociales, económicas, políticas y jurídicas que hicieron de la disputa por la tenencia de la tierra una lucha determinable para el Estado y para ciertos actores económicos que, desde su visión liberal de la sociedad, veían en la tierra un título de poder y especulación económica. Este espectro 
fue tangible en la explotación y acaparamiento de tierras, la semiindustrialización del campo con productos como el arroz y el café y, posteriormente, con la ganadería extensiva y la palma africana. Al respecto, Reyes (2016), señala que:

(...) los conflictos sociales enfrentan adversarios colectivos que disputan el control de un campo común de intereses, para redistribuir las cargas y beneficios de una relación social que se percibe injusta por parte de una (o varias) de las partes que intervienen. Por definición, todo conflicto es limitado, porque el interés común de los adversarios es menester la relación social que los vincula. Cuando las posibilidades de acción de los adversarios no tienen límites, el conflicto deja de existir como tal y se transforma en una empresa reciproca de aniquilación. (p. 43)

En el caso de la relación Estado, campesinos y grupos sociales de la elite regional, esta balanza de poderes desencadenó un tipo de violencia armada que, a diferencia de la denominada época de La Violencia, organizó a los distintos actores en una disputa bélica fortalecida técnica y profesionalmente en el hacer de la guerra. La trasformación del lenguaje con el cual el movimiento campesino, como es el caso de la ANUC, refirió sus reclamaciones, le proporcionó algunas conquistas legales que dieron lugar a la creación de entidades encargadas de la adjudicación y distribución de baldíos, como fue el Instituto Colombiano para la Reforma Agraria (Incora). Sin embargo, también constituyó una oportunidad para que posteriormente, los grupos políticos, sociales y económicos regionales orquestaran una serie de acciones violentas para la apropiación de la tierra como propiedad agraria en todo el territorio periférico nacional. La persistencia de la desestructuración social heredada de los siglos anteriores legitimó a actores distintos al Estado para crear mecanismos opresivos respecto de la población campesina, y poder así, arrebatar su derecho a la tierra (Reyes, 2016).

En este contexto, el ordenamiento jurídico fue un instrumento de alistamiento para la violencia (Cover, 2002) ${ }^{10}$, en tanto las instituciones y la legalidad que se ejercería sobre las comunidades campesinas en las décadas siguientes, desencadenarían actos constitutivos de apartheid sobre la tenencia y disposición de la tierra ${ }^{11}$.

La asociación de los sujetos campesinos con los terratenientes y políticos representó una nueva forma de bienestar o la concreción de un enemigo legítimo, pues el nuevo concepto de propiedad sobre los territorios que ocupaban las cla-

10 Algunos autores como Robert Cover (2002), señalan al derecho como instrumento de violencia debido a su poder de coerción legítimo contra los administrados.

11 En Colombia, al igual que en la Europa premoderna, como lo explica de manera genérica Hobsbawn (2018): "la posesión de una o dos vacas, un cerdo y unos cuantos gansos, eleva[ro]n el concepto al campesino sobre sus hermanos de igual condición social... vagando tras su ganado adquier[ió] el hábito de la indolencia... El trabajo diario se le hace desagradable; la aversión aumenta con el abandono" (p. 153). 
ses campesinas imprimió coerción sobre los desposeídos o sobre quienes, aun teniendo la propiedad de la tierra, no podían explotarla por falta de recursos o, aquellos que tenían a cuestas embargos producto de los créditos agrarios (Molano, 2016). Esta situación originó, de nuevo, la conformación de bandos sociales en disputa, que desencadenó la violencia armada de los siglos XX y XXI.

Tal como lo relata Arturo Alape (1989) y como más adelante lo reafirmaran los profesores Uribe (2007) y Molano (2016), el inicio del conflicto contemporáneo en Colombia, al menos con las FARC-EP, según el mito de Marquetalia, traspasa la barrera del bombardeo efectuado en aquella "República independiente" en 1964, dado que, en dicho acontecimiento, no solo se dio el ataque del Estado sobre las organizaciones campesinas comuneras sino que, además, se hizo evidente el inconformismo y los deseos de una elite del país. Dicha guerrilla nació del movimiento agrario de Marquetalia que posteriormente se convertiría en autodefensa regular (Molano, 2016, p.70).

En tal sentido, los grupos insurgentes activos en áreas rurales colombianas, como las FARC-EP o el Ejército Popular de Liberación (EPL), tenían verdaderos poderes político-territoriales, debido a que crearon raíces en zonas de colonización campesina. Sin embargo, el surgimiento del paramilitarismo a mediados de los ochenta significó que, durante los últimos años, se destruyeran las bases sociales y partisanas de las guerrillas. Este es un factor que ha contribuido, de manera creciente y peligrosa, a la militarización de grupos como las FARC-EP (Orozco, 2006).

Por otro lado, organizaciones como el Ejército de Liberación Nacional (ELN), que hicieron tránsito del foquismo (Guevara, 2019), a la lucha popular prolongada, dieron lugar a un frente político como fue a luchar, lo que los hizo determinantes en las protestas campesinas de 1987 y 1988.

\section{Consecuencias de la guerra prolongada sobre la tierra}

El contexto de violencia producido en la segunda mitad del siglo XX en Colombia, dio lugar al conflicto armado contemporáneo. Como se mencionó, durante las últimas décadas se han vivido varias olas de despojo violento de la tierra (tanto físico como jurídico), bajo los patrones más variados y sofisticados. Este despojo ha producido un fenómeno considerado como una contrarreforma agraria por su efecto de propiciar una mayor concentración de la tierra. En tal sentido, (i) la inequitativa distribución de la propiedad rural; (ii) la informalidad en la tenencia; (iii) los conflictos por el uso y la tenencia de las tierras; y (iv) el proceso contemporáneo de despojo armado de tierras, son las variables que han dado lugar a la concepción de un derecho a la tierra. El profesor Sánchez (2017) señala qué:

El concepto de la tierra demuestra la complejidad de encasillar la discusión sobre los objetivos e intereses de la justicia transicional en 
simples términos de adscripción jurídica a una cierta clase de derechos. Las intervenciones a la tierra dependerán tanto del significado que se le otorgue como del modelo de intervención que se use. Allí, la discusión rígida sobre tipos de derechos parece desvanecerse. De la relación con la tierra pueden depender un variado número de relaciones jurídicas que involucran distintos derechos. (p. 107)

Como se observó en la primera parte del texto, al inicio de la República, la concepción de la tierra se alimentaba de varias fuentes sociales: el Estado como órgano institucionalizado, los terratenientes como elite protectora de sus intereses individuales, y las organizaciones campesinas, de manera que, con los logros alcanzados por otros movimientos de resistencia agraria, crearon una visión cultural, social y política alrededor del territorio que ellos ocupaban. Seguidamente, la consolidación de movimientos políticos locales y su injerencia en los sujetos campesinos, llevaron a un acoplamiento de visión de la propiedad, que fue institucionalizada a través de la Ley. Finalmente, la Constitución de 1991 trajo consigo la promesa del acceso progresivo a la propiedad rural. No obstante, la violencia armada, el despojo de tierras y el desplazamiento forzado llevaron a un replanteamiento de las fuentes de este derecho, pues ya no se iba a hablar de campesinos, sino de desplazados y, posteriormente, de víctimas del conflicto.

\section{Constitucionalización del derecho a la tierra}

El conflicto armado colombiano ha intervenido en la definición de instituciones estáticas como la propiedad, a partir de los avances del constitucionalismo y del sistema internacional de derechos humanos. En ese sentido Buis (2020) hace hincapié en lo siguiente:

Con el surgimiento de los derechos humanos en el siglo XX -entendidos como aquellos derechos que, con foco en la dignidad, todos los seres humanos compartimos sobre la base de la igualdad y la no discriminación-, se ha discutido acerca de los elementos concretos de la propiedad que, lejos de abarcar todo dominio sobre lo material, contribuyen a nuestro desarrollo vital y, por lo tanto, son susceptibles de integrar esa categoría normativa (p. 46)

A continuación, se muestra cómo, sin dejar de lado la visión liberal de la propiedad, la Corte Constitucional y el legislador colombiano, han entendido la propiedad no tanto "como una relación de apropiación entre personas y cosas, sino más bien [a partir] de imaginar de qué modo ellas resultan esenciales para la plena realización del proyecto de vida en conjunto con los otros derechos de que gozamos" (Buis, 2020, p. 46). 


\section{Desplazamiento forzado y derecho a la tierra}

La Constitución Política de 1991 en el artículo 64, señala que: “(...) es deber del Estado promover el acceso progresivo a la propiedad de la tierra de los trabajadores agrario(s) (...)". Sin embargo, el desconocimiento de los derechos de los sujetos campesinos, así como de su condición de víctimas del desplazamiento forzado, mostró la ausencia de una política de Estado para afrontarlo. Así lo confirmó el Secretario General de Naciones Unidas, Francis M. Deng, quien afirmó que: "El gobierno de Colombia no posee estadística alguna sobre el número de desplazados internos" (ONU, 1994, párr. 10) ${ }^{12}$.

En ese contexto, en el año 1995 se profirió el documento Conpes 2804, por medio del cual se aprobó el Programa Nacional de Atención Integral a la Población Desplazada por la Violencia, entre tanto las cifras de víctimas del desplazamiento forzado iban en aumento. En ese marco se crearon tres líneas de atención a la situación de los desplazados: (i) el programa de prevención del desplazamiento, (ii) la consolidación y estabilización socioeconómica, y (iii) la atención social en las áreas de salud, educación, vivienda y empleo. Sin embargo, no se mencionó la protección de sus territorios, ni su reconocimiento como cuerpo social, mayormente campesino.

En este marco, la Corte Constitucional colombiana profirió la Sentencia T-025 de 2004 en la que, en primer lugar, declaró un estado de cosas inconstitucionales y, además, reconoció la existencia de un conflicto armado, de sus víctimas y de la necesidad de proteger sus bienes. Sin embargo, no entró en detalle sobre la población campesina desplazada y sobre la necesidad de protección de sus territorios.

Posteriormente, en dos autos de seguimiento al cumplimiento de esta sentencia la Corte ordenó: (i) implementar planes específicos de protección y atención para las comunidades emblemáticas; (ii) poner en marcha un plan de caracterización de los territorios colectivos y ancestrales habitados por la población indígena y afrocolombiana; (iii) activar la ruta étnica de protección de tierras; (iv) crear una estrategia para la efectiva y oportuna atención humanitaria de emergencia; y (v) diseñar un plan integral de prevención y atención para esta población (planes de salvaguardas) (Corte Constitucional, Autos 004 y 005 de 2009). $\mathrm{Al}$ respecto, es interesante que ninguna de estas providencias señaló la protección de los derechos territoriales de las comunidades campesinas, ni siquiera en clave del derecho a la propiedad.

Posteriormente, el Estado colombiano expidió la Ley 1448 de 2011, Ley de Víctimas y Restitución de Tierras, por medio de la cual incluyó un capítulo dirigido a crear una jurisdicción civil transicional, a través de la que se busca formali-

12 En la década del 90 el desconocimiento de la situación de desplazados internos de las comunidades campesinas y étnicas, se veía reflejado en que quienes prestaban la atención humanitaria no eran las instituciones oficiales sino, que primigeniamente era prestada por el Comité Internacional de la Cruz Roja (CICR), la Iglesia Católica y la Consultoría para los Derechos Humanos y el Desplazamiento (Codhes) (Rodríguez, 2008). 
zar la propiedad de las personas despojadas de sus tierras en el contexto del conflicto armado. Si bien la formalización se da en clave del derecho de propiedad, han surgido procesos subalternos dentro del ritualismo jurídico como el uso de herramientas sociales para determinar las afectaciones de los sujetos de restitución, y en ese orden, se ha logrado caracterizar a la población campesina, a partir de datos sociales de interrelación colectiva y comunitaria, para el manejo de los territorios, las formas de producción y los procesos de soberanía alimentaria.

Sin embargo, este proceso es excepcional y transicional, pues depende de (i) la configuración de un hecho de despojo que haya (ii) ocurrido después del 1 de enero de 1991, (iii) en el marco del conflicto armado. La necesidad de acreditar estos criterios deja atrás a cuerpos campesinos que siguen pugnando por acceder a la tierra, o buscando la protección de sus territorios, y que se encuentran a merced, ya no solo del gran latifundista, sino además de la explotación de hidrocarburos y de la ganadería extensiva.

Según datos oficiales, de 126.322 solicitudes presentadas ante la URT sobre 115.245 predios, en la actualidad han sido resueltas, tanto con trámite hasta los jueces, como rechazadas, 84.126. Finalmente, 5.792 sentencias han sido proferidas para restitución de predios ${ }^{13}$.

Sin embargo, a pesar de que la Corte Constitucional profirió órdenes para garantizar los derechos de las comunidades despojadas por la violencia, en la práctica su materialización ha sido limitada. Además, se pasó por alto el debate inicial relacionado con el "acceso progresivo a la propiedad agraria". Lo anterior, en palabras de Silva y Ramírez (2016), muestra que, en las denominada zonas de violencia, se configura un espacio gris en el que todo derecho, todo formalismo, es inexistente, no solo por la presencia de la violencia sino, principalmente, por la ausencia de instituciones, de interlocutores que conecten al Estado con las necesidades de los sujetos sociales, con sus historias y con sus problemáticas, lo que deviene en un verdadero apartheid constitucional ${ }^{14}$.

\section{Especificación del derecho a la tierra a nivel constitucional: contenido y alcance del derecho a la tierra en el marco del conflicto armado}

El problema planteado en las líneas anteriores encuentra solución en la especificación del derecho a la tierra, o en una redacción más clara y real, en el derecho

Véase: Unidad Especial de Restitución de Tierras: https://www.restituciondetierras.gov.co/estadisticas-de-restitucionde-tierras

14 "El apartheid constitucional es de facto y con ello la eficacia normativa en estas zonas es inexistente, la falta de instituciones fuertes que lleguen a estos territorios y la ineficacia de un Estado Constitucional que brinde verdaderas garantías a los pobladores, hace de estas zonas territorios de violencia configurados como zonas violentas. Zonas compuestas de interlegalidades e ilegalidades, que se nutren del apartheid institucional, que conforman a su vez hechos sociales productores de fuentes normativas, culturales y sociales de violencia" (Silvay Ramírez, 2016, p. 380). 
sobre la propiedad agraria y productiva. La especificación, entonces, significa el reconocimiento de derechos a sujetos y colectivos concretos (específicos) que se encuentran en situaciones especiales, en este sentido Bobbio (1998) se refirió al término como, "el paso gradual, pero cada vez más acentuado, hacia una ulterior determinación de los sujetos titulares de derechos" (p. 109).

En el marco constitucional colombiano, el derecho de las personas desplazadas por el conflicto armado sobre la tierra se ha sustentado en dos fuentes normativas. Por un lado, la normatividad relacionada con la atención, protección y garantía de sus derechos, constituida por la Ley 387 de $1997^{15}$, cuya expedición tuvo como fundamento el deber de solidaridad (artículo 2 constitucional) y, posteriormente, la Ley 1448 de $2011^{16}$, relativa al deber del Estado de reparar a las víctimas, consagrado en el artículo 90 constitucional. De otro lado, la segunda fuente normativa está dada por los desarrollos del derecho internacional de los derechos humanos y del derecho internacional humanitario, los cuales han sido acogidos por medio de las cláusulas remisorias de los artículos 93 y 214 de la Constitución Política, y que conforman el bloque de constitucionalidad (Corte Constitucional, 1995, Sentencia C-225 y Corte Constitucional, 1992, Sentencia C-574).

El punto de partida para el reconocimiento y posterior desarrollo constitucional de este derecho fue la Sentencia T-025 de 2004 a la que ya se hizo mención. En el catálogo de prerrogativas ius fundamentales reconocidas por la Corte Constitucional en tal decisión, se indicó la necesidad de "[q]ue las tierras en posesión o propiedad que fueron abandonadas por los desplazados sean protegidas", además se analizó la política pública sobre el acceso a la tierra de las personas desplazadas forzosamente.

Adicionalmente, en tal providencia se indicó que no se habían implementado los mecanismos para proteger la propiedad o la posesión de las tierras de las personas desplazadas y que los sistemas de registro no incluían la información acerca de los predios abandonados.

En este marco, la Corte Constitucional concretó en el ordenamiento jurídico los componentes del derecho a la tierra en forma de deberes para el Estado y garantías para la población desplazada, en torno a tres situaciones: (i) el registro de los bienes inmuebles, tierras, propiedades y posesiones de las personas desplazada; (ii) la protección de bienes inmuebles, tierras, propiedades y posesiones abandonados o despojados a causa del desplazamiento forzado; y (iii) la adjudicación de tierras. En la Sentencia T-821 de 2007 se agrega como componente al contenido de este derecho: (iv) la restitución de tierras de los

15 “Por la cual se adoptan medidas para la prevención del desplazamiento forzado; la atención, protección, consolidación y esta estabilización socioeconómica de los desplazados internos por la violencia en la República de Colombia".

También llamada Ley de Víctimas y Restitución de Tierras. 
bienes inmuebles despojados ya sea de forma violenta (de hecho), administrativa o jurídica ${ }^{17}$.

Posteriormente, la Corte hizo hincapié en que el deber de reparar a las personas despojadas y desplazadas forzadamente implica la existencia de una obligación estatal de implementar acciones tendientes, entre otros aspectos, a (i) conservar la propiedad o posesión de la tierra, tanto en su perspectiva jurídica como fáctica; (ii) facilitar el retorno al territorio usurpado por los hechos que motivaron el desplazamiento forzado, en condiciones de seguridad; (iii) garantizar que la población campesina propietaria, poseedora o tenedora de la tierra rural, pueda llevar a cabo, tanto su explotación económica, como su uso para vivienda, en condiciones compatibles con los estándares internacionales previstos para ello, estableciendo así, un sistema de derechos interdependientes entre sí (Corte Constitucional, 2011, Sentencia T-076).

En el intermedio del desarrollo del derecho a la restitución de la tierra, la jurisprudencia constitucional profirió varios fallos que ampliaron, al menos desde lo formal, el espectro del acceso a la tierra fuera de las situaciones de conflicto. Se trata de las Sentencias C-077 de 2017, relativa a la constitucionalidad de la Ley Zidres, por medio de la cual se revisó la norma que crea zonas de interés de desarrollo rural, económico y social-zidres-contenido y alcance, y que estableció, como elemento importante para la modificación de una epistemología de la tierra como propiedad, que:

(...) las asociaciones de producción que involucren a los campesinos y trabajadores agrarios, (...) deben reconocer su condición de sujetos de especial protección, que tienen una relación con el territorio en el que viven. Por ello, ha considerado que la reducción de su aporte a la tierra, sin la oportunidad de participar de manera activa en el proyecto desnaturaliza su condición de trabajador agrario o de campesino. (Corte Constitucional, 2017. Sentencia C-077 de 2017)

De otro lado, la Sentencia SU-235/16, unificó el precedente constitucional en cuanto a la presunción de baldíos, enfatizó que: el derecho al acceso a la tierra tiene los siguientes contenidos protegidos: (i) acceso a la tierra, a través de la titulación individual o colectiva de tierras a los pobladores rurales, mediante formas asociativas, de su arrendamiento, de la concesión de créditos a largo plazo,

17 La Corte señaló que la reparación integral supone el derecho a la restitución de los bienes de los cuales la persona ha sido despojada (Corte Constitucional, Sentencia T-821 de 2007 y T-076 de 2011); entre otras medidas. Así las cosas, respecto de quienes hayan sido desplazados forzadamente y, además, despojados violentamente de su tierra, sean propietarios o poseedores, el Estado tiene la obligación de “conser(var) su derecho a la propiedad o posesión y (que se) les restablezca el uso, goce y libre disposición de la misma en las condiciones establecidas por el derecho internacional en la materia. En efecto, en estos casos el derecho a la propiedad o a la posesión adquiere un carácter particularmente, reforzado, que merece atención especial por parte del Estado". Adicionalmente, dicha corporación indicó que el deber de restitución de tierras se encuentra intrínsecamente relacionado con el derecho al retorno y/o a la reubicación (Corte Constitucional, Sentencia T-159 de 2011). 
de la creación de subsidios para la compra de tierra, del desarrollo de proyectos agrícolas, entre otros; (ii) acceso a los recursos y servicios que permitan realizar los proyectos de vida de la población rural como educación, salud, vivienda, seguridad social, recreación, crédito, comunicaciones, comercialización de los productos, asistencia técnica y empresarial; y (iii) seguridad jurídica de las diferentes formas de tenencia de la tierra como la propiedad, la posesión y la mera tenencia, sin que ello signifique que su protección se circunscriba solamente a estas.

En definitiva, el debate actual sobre el derecho al territorio, específicamente su contenido de acceso a la tierra abarca varias relaciones y, como punto importante, la seguridad jurídica que debe brindar el Estado para proteger la conexión que surge entre la población rural y el espacio físico en el cual aspiran desarrollar su proyecto de vida, lo cual trasciende el campo de la aclaración de títulos y los derechos reales sobre bienes.

El análisis precedente muestra que, pese al avance normativo, en Colombia se ha configurado apartheid constitucional en materia de acceso a la tierra para las víctimas. En el siguiente apartado se analiza en qué medida el Acuerdo Final para la Terminación del conflicto modificó tal situación.

\section{La tierra y el acuerdo final para la terminación del conflicto armado}

El primer punto de las negociaciones de paz se denominó "Hacia un Nuevo Campo Colombiano: Reforma Rural Integral", pero, dentro del debate público alrededor del Acuerdo Final, el tema de la tierra no fue uno de los de mayor interés para la sociedad en su conjunto (Tibble, 2017).

En tal sentido, como Latorre (2017) advierte, existe una carencia en la discusión real por el campo, ya que para las elites rurales y para los grandes propietarios en el país, "la tierra y el desarrollo agrario representan uno de los puntos más sensibles del post acuerdo más allá del falso fantasma de la expropiación y la amenaza de la propiedad privada" (p. 213). Ello por cuanto la democratización del sector rural y la transformación de las estructuras locales, representan amenazas reales a su statu quo sobre el control de los territorios, la política y las sociedades periféricas.

A diferencia de otros puntos tratados en el Acuerdo Final, la cuestión de la tierra y la necesidad de una reforma rural integral no tuvo oposición popular, pues como se ha señalado, este asunto ha sido interés para dos sectores: el campesinado colombiano y las élites locales. Esta dinámica social ha impactado en la manera de especificación del derecho a la tierra, o mejor, de la propiedad rural en Colombia ${ }^{18}$.

18 Sobre Este punto ver. Bolívar, A. (2016). 
El Acuerdo Final trató de establecer un punto de partida sobre la concepción del sujeto campesino y su relación con su territorio, lo cual no logró proscribir de la fórmula jurídica el ingrediente principal de la disputa histórica, esto es, su conceptualización como propiedad desde el modelo liberal-formal ${ }^{19}$. Lo anterior por cuanto, dentro de la negociación, las FARC-EP cedieron en algunas de sus posiciones tradicionales en lo referente a la distribución de la tierra y a la protección de la agricultura campesina (De la Calle, 2019, pp. 161,164-166) ${ }^{20}$.

En las modificaciones al Acuerdo se incluyó el principio de desarrollo integral del campo ${ }^{21}$ que "depende de un adecuado balance entre las diferentes formas de producción existentes -agricultura familiar, agroindustria, turismo, agricultura comercial de escala-" (Latorre, 2017, p. 20). Lo anterior, implica la coexistencia entre la agricultura rural campesina y la agroindustria propia de los capitales nacionales y extranjeros. Esta tensión, que aún se encuentra sin definir, parte de dos visiones socioeconómicas en confrontación; el modelo de desarrollo que surge desde una concepción de la tierra como propiedad (liberal-formal), y otra, que se construye desde los sujetos campesinos, sobre quienes la relación con el territorio que se posee no está vinculada a la reproducción del capital, es decir, la prioridad no es la generación de plusvalía a través de la renta eficiente de sus territorios.

El reconocimiento de esta discusión económica, social y política incide en la epistemología del derecho a la tierra y en los programas, proyectos y políticas públicas que se tomen para garantizar su materialización, así como puede incidir en el acceso, la permanencia y la sostenibilidad de la tierra para los sujetos campesinos, mientras que su desconocimiento puede prologar el apartheid constitucional que pone en cuestión la eficacia de las instituciones jurídicas derivadas del constitucionalismo social moderno.

Finalmente, si bien existen algunos intentos desde instituciones internacionales por interactuar con el modelo agrario campesino, como la "Declaración de las Naciones Unidas sobre los derechos de los campesinos y otras personas que trabajan en las zonas rurales", al igual que lo señalado por la Corte Constitucional, son disposiciones limitadas, en su implementación, por una barrera que el mismo derecho impone y que no puede sobrepasar ${ }^{22}$.

19 Ramírez (2019, p. 125) señala que, dentro de las negociaciones del Acuerdo Final para la Terminación del Conflicto, una de las características fue el uso de un discurso técnico y la "especialización del debate" que, en el caso de la inserción del derecho internacional humanitario, fue la limitación de "la intervención de otros actores de base como, como las organizaciones territoriales".

20 Urdaneta (2018, p. 144), sin embargo, destaca en su libro sobre justicias bastardas, que las FARC-EP en los territorios en los cuales tenían dominio y control resolvían conflictos de poseedores de tierras, lo que mantenía un aspecto esencial heredado del sistema liberal descrito y es la tenencia de la tierra como objeto, como propiedad no formalizada.

21 Acuerdo Final para la Terminación Final del Conflicto. Punto 1. 30 de noviembre de 2016.

22 Véase Golay (2019). 


\section{Conclusión}

La historia de las guerras en Colombia, o en mejores términos, del conflicto armado no internacional contemporáneo, se entrecruza con los debates alrededor de la definición, titularidad y posesión de la tierra. Sin embargo, dos rezagos epistémicos entrecruzan el concepto de derecho a la tierra; por un lado, la herencia occidental-europea que vincula a la tierra con la propiedad, es decir, la relación objeto-cosa, pilares fundamentales del Estado y de la sociedad. Por otro lado, la visión desarrollada desde los movimientos campesinos, en general, a partir de su alto grado de cohesión a su arraigo territorial y familiar.

Sin embargo, de la interrelación de estas concepciones epistémicas si se quiere, se puede decir prima facie, que el campesino convencional en Colombia se transmutó en lo que se denomina el colono, aquel sujeto social que hace parte de una comunidad que, en búsqueda de tierra y de mejores condiciones de vida, toma posesión de ciertos territorios agrestes con el fin de darles una vocación productiva, de acuerdo con las formas de producción propias requeridas.

De este modo, la configuración de un derecho a la tierra es, a su vez, la estructuración del campesinado como colectivo social, como un colectivo que ha defendido la tierra como elemento sine qua non de su relacionamiento con el mundo, no solo para efectos de la alimentación y la producción de bienes, sino también desde aspectos abstractos e inmateriales como el bienestar, la vida, la fertilidad, la muerte, etc.

A primera vista, podría afirmarse del relato histórico, que en Colombia dicho relacionamiento ha sido más utilitario que de otro tipo, pues, en realidad, se gestó un colectivo humano de pequeños propietarios que vieron en la propiedad un medio de producción. De igual forma, esto puede asegurarse desde otros sectores como terratenientes, en su primera ola y, posteriormente, agroindustriales y empresas extractivas que vieron en los territorios, y en la posesión de la tierra, una forma utilitaria de renta y de adquisición de poder político y social.

Es en ese contexto que las hordas de despojos y desplazamientos forzados, de parte de grupos armados, conllevó a la configuración de una contrarreforma rural que resignificó el derecho a la tierra como una prerrogativa exclusiva de quienes detentan el poder y las armas y que consolidó la visión de la tierra como propiedad.

En definitiva, dicha situación de la tierra en Colombia es preocupante, ya que el campo ha sido el epicentro de la mayoría de los conflictos en Colombia. Según un estudio realizado en el año 2013, dos años después de expedida la Ley de Víctimas y de Restitución de Tierras, "cerca del 60\% de los municipios que tiene el país deben considerarse rurales y existe, además, población rural dispersa en el resto de los municipios, con lo cual la población rural representa poco más del 30 \% de la población de Colombia" (Ocampo, 2014, p. 4). Lo anterior, muestra la necesidad de que los presupuestos jurídicos alrededor de la tierra sean eficaces. 
Sin embargo, ha sido la Corte Constitucional, a través de su basta jurisprudencia en materia de desplazamiento y despojo forzado en el conflicto armado, quien ha dado significado al derecho a la tierra en el país. Dicha especificación en el ordenamiento jurídico, vía jurisprudencial, ha tenido varios efectos. Por un lado, ha conseguido efectos simbólicos que han dado lugar al establecimiento de un lenguaje jurídico que da cuenta de la falta de acceso a la tierra, el despojo y el abandono forzado de tierras del campesinado, así como de la inexistencia de una política pública fuerte para la garantía de los derechos al territorio y a la propiedad rural. Así mismo, esta jurisprudencia ha gestado la creación de algunas instituciones de parte del Estado y de regulación normativa, como fue la expedición de la Ley de Víctimas y de Restitución de Tierras.

Estas especificaciones del derecho han llevado a que la propiedad agraria se haya construido desde una visión liberal-occidental ligada al desarrollo económico. Lo anterior, ha incidido en la falta de acceso de los sujetos campesinos y en los diferentes bloqueos que se han generado desde las élites y desde algunas instituciones del Estado, en la restitución de tierras. Estos bloqueos impiden el reconocimiento pleno de los derechos del campesinado y mantienen el apartheid constitucional, en tanto, si bien las normas se dirigen a este grupo social, pueden terminar beneficiando a los grandes latifundistas e inversores de la agroindustria. Esto, además, desconoce los postulados y las ínfimas adecuaciones del constitucionalismo aspiracional de Querétaro frente a la distribución de la tierra desde la premisa la tierra pa el que trabaja.

En consecuencia, la especificación de la tierra como derecho ha sido llevado hacia un concepto de propiedad rural por dos razones fundamentales que desconocen el modelo social: (i) por la incidencia de las elites regionales sobre los territorios y su intención de apropiación y acaparamiento de tierras a través de la violencia armada e institucional y (ii) porque pese al reconocimiento de ciertas prerrogativas para grupos vulnerables, se mantiene la idea liberal de la propiedad.

Finalmente, como lo sostiene el Programa para el Desarrollo de Naciones Unidas (PNUD), el acceso a la tierra ha sido un espacio rezagado al proceso de modernización, en parte porque "el modelo de desarrollo y la modernización han ignorado y desvalorizado lo rural, porque ha visto a los conglomerados urbanos como opción más viable para alcanzar el progreso y lograr mejores niveles de vida" (Programa de las Naciones Unidas para el desarrollo, 2011, p. 30), lo que condena al campesinado colombiano a vivir entre la resistencia por el derecho a la tierra y el apartheid constitucional.

\section{Referencias bibliográficas}

Báez, M. (2009). Tierras sin ley. La colonización del Oeste de Estados Unidos. Buenos Aires: Anthropos. 
Bobbio, N. (1988). El tiempo y los derechos. Madrid: Sistema.

Barreto, A. (2011). Venturas y desventuras de la regeneración: Apuntes de historia jurídica sobre el proyecto político de 1886 y sus transformaciones y rupturas en el siglo XX. Bogotá: Universidad de los Andes.

Bolívar, A. (11 de julio de 2016). Restitución de tierras: problemas y tareas pendientes. Razón Pública. Recuperado de https://www.razonpublica.com/ index.php/conflicto-drogas-y-paz-temas-30/9570-restituci\%C3\%B3n-detierras-problemas-y-tareas-pendientes.html

Buis, E. (2020). Tierras comunales y bienes civiles en la jurisprudencia de la Corte Interamericana de Derechos Humanos: una interpretación de la propiedad desde el Nuevo Materialismo. En Tendencias Jurisprudenciales de la Corte Interamericana de Derechos Humanos (pp. 45-61). Porto Alegre: Dovogado Editora.

Camaroff, J. (2009). Violencia y ley en la poscolonia: una reflexión sobre las complicidades Norte-Sur. Buenos Aires: Katz.

Cano, L. (2015). Objetivar el derecho para distribuir el poder: León Dugit. En I. C. Jaramillo (ed.), Derecho y poder. Aportes al canon transaccional (pp. 191-212). Bogotá: Universidad de los Andes.

Centro Nacional de Memoria Histórica. (2010). La Tierra en disputa. Recuperado de //www.centrodememoriahistorica.gov.co/informes/informes-2010/ la-tierra-en-disputa

Centro Nacional de Memoria Histórica (CNMH). (2010). La Tierra en disputa. Recuperado de //www.centrodememoriahistorica.gov.co/informes/informes-2010/la-tierra-en-disputa

Centro Nacional de Memoria Histórica (CNMH). (2015). Informe nacional del desplazamiento forzado en Colombia. Una nación desplazada. Recuperado de http://www.centrodememoriahistorica.gov.co/descargas/informes2015/ nacion-desplazada/una-nacion-desplazada.pdf

Centro Nacional de Memoria Histórica (CNMH). (2015 a). Con licencia para desplazar. Masacres y reconfiguración territorial en Tibú, Catatumbo. Recuperado de http://www.centrodememoriahistorica.gov.co/descargas/informes2015/ nacion-desplazada/con-licencia-para-desplazar.pdf

Centro Nacional de Memoria Histórica (CNMH). (2016). Tierras y conflictos rurales. Historias políticas agrarias y protagonistas. Recuperado de http:// centrodememoriahistorica.gov.co/wp-content/uploads/2020/01/tierrasy-conflictos-rurales.pdf

Colombia. Corte Constitucional. (18 de mayo de 1995). Sentencia C-225/95. [MP Alejandro Martínez Caballero].

Colombia. Corte Constitucional. (22 de enero de 2004). Sentencia T- 025/04. [MP Manuel José Cepeda]. 
Colombia. Corte Constitucional. (5 de octubre de 2007). Sentencia T-821/07. [MP Catalina Botero Díaz Marino].

Colombia. Corte Constitucional. (26 de enero de 2009). Auto 005. [MP Manuel José Cepeda Espinosa].

Colombia. Corte Constitucional. (26 de enero de 2009). Auto 004. [MP Manuel José Cepeda Espinosa].

Colombia. Corte Constitucional. (8 de febrero de 2011). Sentencia T-076/11. [MP Luis Ernesto Vargas Silva].

Colombia. Corte Constitucional. (10 de marzo de 2011). Sentencia T-159/11. [Humberto Antonio Sierra Porto].

Colombia. Corte Constitucional. (12 de mayo de 2016). Sentencia SU-235/16. [MP Gloria Stella Ortiz Delgado].

Colombia. Corte Constitucional. (8 de febrero de 2017). Sentencias C-077/17. [MP Luis Ernesto Vargas Silva].

Colombia. Presidente de la República. (27 de septiembre de 2001). Decreto 2007 de 2001. Por el cual se reglamenta parcialmente los artículos 7o., 17 y 19 de la Ley 387 de 1997, en lo relativo a la oportuna atención a la población rural desplazada por la violencia, en el marco del retorno voluntario a su lugar de origen o de su reasentamiento en otro lugar y se adoptan medidas tendientes a prevenir esta situación. Diario Oficial n.o 44564.

Comisión de Seguimiento a la política pública sobre desplazamiento forzado. (2010). Comisión de Seguimiento a la Sentencia T-025 de 2004. III Encuesta Nacional de Verificación de los derechos de la población desplazada.

Congreso Constituyentes del Estado libre y soberano de Querétaro Arteaga. (1917). Constitución Política del Estado Libre y Soberano de Querétaro Arteaga. Recuperado de https://archivos.juridicas.unam.mx/www/bjv/libros/7/3135/18.pdf

Comisión Histórica del Conflicto y sus Víctimas. (2015). Contribución al entendimiento del conflicto armado en Colombia. Bogotá: Desde abajo.

Cover, R. (2002). Derecho, narración y violencia. Poder constructivo y poder destructivo en la interpretación judicial. España y EE. UU: Gedisa, Yale Law School.

Cruz, L. (2010). La constitución política de 1991 y la apertura económica. Revista de la Facultad de Ciencias Económicas de la Universidad Militar Nueva Granada, XVIII (1). Recuperado de http://www.scielo.org.co/scielo.php?script=sci_ar ttext\&pid=S0121-68052010000100016" http://www.scielo.org.co/scielo. php?script=sci_arttext\&pid=S0121-68052010000100016

De la Calle, H. (2019). Revelaciones al final de una guerra. Testimonio del Jefe Negociador del Gobierno Colombiano en la Habana. Bogotá: Debate.

De Sousa, B. (2009). Una epistemología del Sur. México: Clacso, Siglo XXI. 
Estrada, J. (2015). Acumulación capitalista, dominación de clase y rebelión armada. En Contribución para el esclarecimiento del conflicto (pp. 295-358). Bogotá: Desde abajo.

Gaviria, E. (2002). El liberalismo y la insurrección de los artesanos contra el librecambio. Bogotá: Universidad Jorge Tadeo Lozano.

Guevara, E. (2019). La Guerra de Guerrillas. Ciudad de México: Oceansur.

Golay, C. (5 de marzo de 2019). Outlines Steps Towards The Implementation of The Un Declaration On The Rights Of Peasants. Recuperado de https://www. geneva-academy.ch/news/detail/215-new-publication-outlines-steps-towards-the-implementation-of-the-un-declaration-on-the-rights-of-peasants

Guilli, A. (2007). La revolución interrumpida. Ciudad de México: Ediciones ERA.

Gutiérrez, F. (2014). El orangután con sacoleva. Cien años de democracia y represión en Colombia (1910 y 2010). Bogotá: Debate.

Hobsbawn, E. (1968). Rebeldes y primitivos. Estudio sobre las formas arcaicas de los movimientos sociales en los siglos XIX y XX. Barcelona: Ariel.

Hobsbawn, E. (2018). La era de la revolución. 1789-1848. Bogotá: Booket.

Holdcroft, L. (1991). Grandeza y decadencia del desarrollo comunitario, 19501965. En C. Eicher y J. Staatz (eds.), Desarrollo agrícola en el Tercer Mundo (pp. 62-76). Ciudad de México: Fondo de Cultura Económica.

Kissinger, H. (2016). Un nuevo orden Mundial. Reflexiones sobre el carácter de los países en el curso de la historia. Bogotá: Debate.

La Oficina del Alto Comisionado para la Paz. (2016). Acuerdo final para la terminación del conflicto y la construcción de una paz establey duradera. Recuperado de https://www.refworld.org.es/docid/5a8744d54.html

Latorre, S. (2017). El debate por la propiedad de la tierra, el punto por donde debe comenzar una pedagogía de la paz. En L. M. Céspedes-Báez y E. Prieto-Ríos (eds.), Utopía u oportunidad fallida. Análisis crítico del Acuerdo de Paz (pp. 211-243). Bogotá: Universidad del Rosario.

Legrand, C. (2017). Colonización y protesta en Colombia (1850-1950). Bogotá: Universidad de los Andes.

Marulanda, E. (1991). Colonización y Conflicto. Lecciones del Sumapaz. Bogotá: IERPRI.

Marx, C. (2014). El Capital (vol. I). Madrid: Akal.

Molano, A. (2013). Dignidad campesina. Entre la realidad y la esperanza. Bogotá: Icono.

Molano, A. (2016). A lomo de mula. Viajes al corazón de las Farc. Bogotá: Penguin Random House. 
Molina, G. (1984). Breviario de Ideas Políticas. Bogotá: Ediciones Tercer Mundo.

Ninet, (2017). La Constitución de Querétaro. Revolución y constitución, aspectos originales y sugestivos desde el derecho constitucional comparado. Cuestiones constitucionales, 36, 271-299.

Palacios, M. A. (2014). ¿De quién es la tierra? Propiedad, politización y protesta campesina en la década de 1930. Bogotá: Universidad de los Andes.

Pérez, J. M. (2010). Luchas campesinas y reforma agraria. Memorias de un dirigente de la ANUC en la costa caribe. Bogotá: Puntoaparte Editores.

Pizarro, E. (9 de mayo de 2004). Marquetalia: el mito fundacional de las Farc. UNP n. $\underline{o}$ 57. Recuperado de http://historico.unperiodico.unal.edu.co/ediciones/57/03. htm» http://historico.unperiodico.unal.edu.co/ediciones/57/03.htm

Ocampo, J. (2014). Misión para la transformación del campo. Marco conceptual para la transformación del campo. Bogotá: Departamento Nacional de Planeación (DNP).

Organización de las Naciones Unidas (ONU). (1998). Intensificación de la promoción y el fomento de los derechos humanos y las libertades fundamentales, en particular la cuestión del programa y los métodos de trabajo de la comisión. (54). Recuperado de https://www.acnur.org/fileadmin/Documentos/ BDL/2001/0022.pdf

Organización de Naciones Unidas (ONU). (1994). Ulterior promoción y fomento de los derechos humanos y las libertades fundamentales, con inclusión de la cuestión del programa y los métodos de trabajo de la Comisión Derechos humanos, éxodos en masa y personas desplazadas. Informe del Representante del Secretario General, Sr. Francis Deng, presentado en cumplimiento de la resolución 1993/95 de la Comisión de Derechos Humanos. Recuperado de https:// www.hchr.org.co/documentoseinformes/documentos/html/informes/onu/ resdi/E-CN-4-1995-50-ADD-1.html

Organización de Naciones Unidas (ONU). (2018). United Nations Declaration on the Rights of Peasants and Other People Working in Rural Areas. Resolution adopted by the General Assembly on 17 December 2018.

Orozco, I. (2006). Combatientes, rebeldes y terroristas. Guerra y derecho en Colombia. Bogotá: Temis.

Programa de las Naciones Unidas para el desarrollo (PNUD). (2011). Colombia rural: Razones para la esperanza. Informe nacional de Desarrollo Humano. Recuperado de https://www.undp.org/content/dam/colombia/docs/DesarrolloHumano/undp-co-ic_indh2011-parte1-2011.pdf

Sánchez, G. (1984). Los días de la revolución. Gaitanismo y 9 de abril en providencia. Bogotá: Centro Cultural García Márquez. 
Sánchez, N. (2017). Tierra en Transición. Justicia transicional, restitución de tierras y política agraria en Colombia. Bogotá: Dejusticia.

Silva, P. y Ramírez, G. C. (2016). Fórmulas para la Paz: Eficacia de los derechos humanos en las zonas de violencia y los campos sociales minados por el capitalismo global. En Paz a través del Derecho y de la Constitución (Serie Constitucionalismo Científico) (pp. 373-390). Bogotá: Grupo Ibáñez.

Spivak, G. (1998). Editor's Note. En R. Guha \& G. Spivak (eds.), Sulbartern Studies: Deconstructing Historiography. Oxford: Oxford Press.

Ramírez, G. C. (2015). Entrevista víctimas de despojo de tierras en el marco de los procesos de restitución de tierras llevados por la Comisión Colombiana de Juristas. [Entrevista archivo personal]

Ramírez, G. C. (2019). Una visión socio jurídica del derecho internacional humanitario en el marco del proceso de paz en Colombia. En N. C Sánchez León (ed.), Justicia Transicional en pugna. El rol del derecho en la construcción de paz en Colombia (pp. 121-161). Bogotá: Universidad Nacional de Colombia.

Reyes, A. (2016). Guerreros y campesinos. Despojo y restitución de tierras en Colombia. Bogotá: Ariel.

Rodríguez, C. (2008). Más allá del desplazamiento. Políticas, derechos y superación del desplazamiento forzado en Colombia. Bogotá: Colección Estudios CIJUS.

Rodríguez Franco, D. y Rodríguez Garavito, C. (2015). Juicio a la exclusión. El impacto de los tribunales sobre los derechos sociales en el Sur Globa. Buenos Aires: Siglo XXI, Dejusticia.

Tibble, C. (25 de mayo de 2017). La tierra en Colombia es de unos pocos. Revista Semana. recuperado de https://www.semana.com/libros/articulo/el-problemade-la-tierra-albsalon-machado-entrevista/63834/

Urdaneta, F. (2018). Justicias bastardas. Estudios sobre la administración de justicia por las FARC-EP en el suroriente de Colombia. Bogotá: Universidad Nacional de Colombia.

Uribe, M. (2007). Salvo el poder todo es una ilusión. Bogotá: Instituto Pensar.

Uribe, M. (2017). Antropología de la inhumanidad. Bogotá: Edit. Uniandes.

Zelik, R. (2015). Paramilitarismo. Violencia y transformación social, política y económica en Colombia. Bogotá: Siglo del Hombre. 